\title{
LIBROS Y LIBRERÍAS: LA RECEPCIÓN DE COMMYNES EN ESPAÑA ${ }^{1}$
}

\author{
SÒNIA BOADAS \\ Universitat Autònoma de Barcelona \\ sonia.boadas@gmail.com
}

$\mathrm{U}$

n breve repaso biográfico a la figura de Philippe de Commynes (14471511), señor de Argentón, nos indica que fue un escritor, consejero y diplomático francés que estuvo al servicio de dos monarcas rivales. Pasó su juventud en Borgoña, bajo el reinado de Felipe el Bueno, y posteriormente sirvió a su hijo y sucesor, Carlos el Temerario, también duque de Borgoña, de quien fue chambelán y confidente. Estuvo al mando de varias misiones diplomáticas en el extranjero que lo llevaron a Inglaterra y a España, pero lo que realmente marcó su devenir fue su presencia en el encuentro que tuvieron Carlos I de Borgoña y Luis IX de Francia, en Péronne (1468). Pocos años después de esa reunión, en 1472, Commynes abandonó la causa borgoñona y se puso a las órdenes del rey Luis XI, pasando a ser uno de los favoritos del monarca francés, su principal representante diplomático $\mathrm{y}$, no menos importante, uno de los que conocía más de cerca a su principal enemigo. Después de la muerte de Luis XI en 1483, Commynes cayó en desgracia y fue puesto en prisión por haber confabulado con Luis de Orléans, el futuro Luis XII, para hacerse con el poder que regentaba Ana de Beaujeu durante la minoría de edad de Carlos VIII. Esto le obligó a pasar unos años alejado de la corte francesa: fue enviado a la Guerra de Italia (1494-1495), y posteriormente desempeñó algunas labores diplomáticas en Venecia y Milán. Cuando regresó a Francia, con Luis XII en el trono, permaneció en un segundo plano en la vida política y apartado de las funciones públicas hasta que murió en 1511.

\footnotetext{
1 El presente trabajo se inscribe en el Proyecto de Investigación FFI2011-22929 («Diego de Saavedra Fajardo y las corrientes intelectuales y literarias del Humanismo»), financiado por el Ministerio de Economía y Competitividad.
}

Edad de Oro, XXXIV (2015), pp. 101-114, ISSN: 0212-0429 - DOI http://dx.doi.org/10.15366/edadoro2015.34.006 
Sus vivencias personales, la relación que mantuvo con ambos monarcas y el carácter y las estrategias políticas de los mismos, quedaron debidamente plasmadas en las Mémoires de messire Philippe de Comynes, cuya editio princeps no pasó por los tórculos de la imprenta hasta 1524 (Paris, Galliot du Pré) $)^{2}$. En sus páginas se narran las vicisitudes de estos dos monarcas franceses, analizando su conducta con extrema sutileza y donde la historia es concebida con finalidades morales, con claro predominio de la prudencia y en la que se muestran lúcidamente todas las facetas del universo político: desde la disimulación hasta la deslealtad, pasando por el engaño, la astucia, la desconfianza y la codicia.

La obra se convirtió rápidamente en un gran éxito editorial francés y a mediados del siglo Xvi ya habían salido a la luz las primeras traducciones de la obra al latín, al italiano y al alemán, cuya primera edición fechaba de $1551^{3}$. En la década de los setenta apareció la primera traducción al holandés, mientras que las traducciones al inglés y al español se publicaron a finales de siglo: la princeps española no se imprimió hasta 1586, de la mano del secretario de Felipe II en París, Pedro de Aguilón, quien optó por hacer una paráfrasis del texto francés (García López 2103: 47-49); mientras que la versión inglesa apareció en Londres el $1596^{4}$.

Para calibrar la presencia que tuvieron las Memorias de Commynes, y consecuentemente la influencia que pudo ejercer su obra en la España de finales del siglo XVI y principios del XVII, hemos realizado un rastreo documental en los catálogos de las principales bibliotecas de la época. El resultado de la búsqueda es sorprendente, ya que las obras del señor de Argentón aparecen en una gran variedad de librerías españolas, desde bibliotecas de la alta nobleza, bibliófilos, pintores o mecenas literarios, hasta la misma biblioteca real.

Son varias las librerías que contaban con ejemplares de las Mémoires en francés o en su traducción italiana. En la biblioteca de Jerónimo Zurita se conservaba un ejemplar de la historia de Commynes en octavo («Historia de Mosen Argenton in

2 El título de la princeps rezaba Cronique et hystorie faicte et composée par feu Messier Phelippe de Commines... contenant les choses advenues durant le règne du roy Louys Xve, tant en France, Bourgogne, Flandres, Arthois, Angleterre que Espaigne et lieux circonvoisins.

3 Además de las traducciones al italiano y latín que señala García López (2013: 46), reseñamos aquí la princeps alemana: Histori, Ursprung und Ursach des Burgundischen Kriegs: so sich zwischen König Ludwigen inn Franckreich, dem XI diß Namens, vnd H. Carle von Burgund, Schweitzern vnd den Teutschen, verlauffen, Straßburg, Wendel Rihel, 1551.

4 La versión holandesa rezaba Historie van coninck Lodovick van Vranck-rijck den elfsten, dies naems, ende van hertogh Carle van Borgondien, Antwerpen, François van Ravelenghien, 1578; y la inglesa llevaba por título: The historie of Philip de Commines Knight, Lord of Argenton, London, 1596. Asimismo, hemos podido documentar una versión sueca de la obra publicada en 1624: Philippi Cominei Grundelighe beskrifwelse om allehanda wichtige handlingar, som emellan konung Ludwijk then elleffte, medh thet nampnet, aff Frankrijke, och then nampnkunnige krijgshiälten hertigh Carl aff Burgund, Stockholm, Ignatium Meurer, 1624. 
$8^{\circ}$ en paperon en quero por 8 reales») que Domingo Malvedí (2010: 111) ha relacionado con una edición italiana publicada en Venecia. También eran italianas las dos ediciones que el inquisidor Gabriel Sora poseyó en su biblioteca (Gutiérrez 1977: 232). Por su parte, Joaquim Setantí, aunque no citara directamente al de Argentón en sus colecciones de aforismos, estaba en posesión de un ejemplar italiano de las Memorias, en este caso de una edición impresa en Milán el 1610 (Espino López 2001: 49; García López 2013: 60). El erudito aragonés Juan de Lastanosa también custodiaba un ejemplar de las Memorias de Commynes en su biblioteca («Felipe Comines. Compendio de sus memorias, 1582», IBSO: LAST264) ${ }^{5}$, un volumen que incluso pudo haber consultado Baltasar Gracián.

La nobleza española también se interesó por las obras de Commynes y en sus bibliotecas se custodiaron varios ejemplares de las Mémoires, ya fuera en su versión francesa o en traducciones italianas o inglesas. En el inventario que en 1626 se hizo de la biblioteca de Ruy Gómez de Silva, III duque de Pastrana, ya constaba un volumen de Commynes: «Otro libro de la memoria de Phelipe de Comes» (Dadson 1987: 252; IBSO: RGS203). En la biblioteca que don Antonio Juan Luis de la Cerda, VII duque de Medinaceli, tenía en el palacio del Puerto de Santa María también se encontraba otro ejemplar del de Argentón: «Phelipe Comines Sobre los / hechos de Luis Vndézimo, tomo / en octabo, en ocho reales», que Álvarez Márquez (1988: 73) identificó con la edición latina De rebus gestis Ludovici, eius nomine undecimi, Galliarum Regis, et Caroli, Burgundiae Ducis... commentarii. También en el catálogo de los libros de Diego de Silva y Mendoza, conde de Salinas, realizado por los alrededores de 1617, constaba un volumen de las crónicas de Commynes («Delle memorie del signore de Argentone»), que Dadson (1998: 400) relacionó con la edición milanesa de 1610; así como en la biblioteca del conde de Gondomar, don Diego Sarmiento de Acuña, donde se custodiaban dos ediciones de la obra: una edición inglesa, impresa en Londres el 1601, y otra francesa, publicada en París el 1615 (IBSO: CG-II, 604 y CGII, 612). Asimismo, Francisco de Mendoza, obispo de Sigüenza y almirante de Aragón, también tuvo en su poder otro ejemplar de las memorias del historiador francés (Dadson 2008: 279) $)^{6}$.

$5 \quad$ Para las labores de localización de ejemplares, además de todas las referencias bibliográficas citadas, nos han sido muy útiles los datos facilitados por el portal online IBSO (Inventarios y Bibliotecas del Siglo de Oro) del grupo de investigación BIDISO de la Universidade da Coruña. Los números que se facilitan son las claves de identificación de los registros. No hemos podido documentar ninguna edición de 1582. Quizá se trate de la edición francesa que se publicó en París el 1580 .

6 Dadson (1998: 424, 434) apunta a que algunos de los libros descritos en el catálogo de Brianda de la Cerda, duquesa de Béjar, y de Antonia de Ulloa, duquesa de Salinas, podrían ser también ejemplares de las Memorias de Commynes, aunque la sucinta descripción de los mismos no permite afirmarlo. 
En 1643 se publicó en Amberes la segunda impresión española de las Memorias hecha por Juan de Vitrián, que seguramente estaba redactada en la década de los veinte, ya que las licencias de impresión fechan de 1625. Se trataba de una lujosa edición que contenía emblemas y motes políticos, donde Vitrián no solo traducía el texto de Commynes sino que lo complementaba con comentarios y anotaciones de cuño político, una obra que ponía de manifiesto la relevancia que estaba teniendo el historiador francés en los libros de teoría política de la primera mitad del siglo XVII ${ }^{7}$. En el prólogo, Vitrián ponía énfasis en su concepción de la Razón de Estado desde una mentalidad ortodoxa: «Concurrieron en este libro para universal enseñanza buen autor y buen sujeto: el autor ingenioso, político, pío y cristiano, descubridor de secretos y verdades, y amigo de ellas».

A diferencia de la traducción del secretario Aguilón, hecha más de cincuenta años antes y que no hemos encontrado reseñada en ninguna librería, la edición de Vitrián tuvo una acogida notable y pronto llamó la atención de los hombres cultos del momento ${ }^{8}$. Este es el caso, por ejemplo, de don Pedro de Arce y Reinoso, cuya biblioteca contaba con un ejemplar que rezaba «Commines, Memorias... con escolios de don Juan de Vitrián» (Gutiérrez 1977: 220). Otro ejemplar de la traducción de Vitrián se encontraba en la librería del marqués de Montealegre, en cuyo catálogo de libros aparecía la siguiente referencia: «Commines, las Memorias... traducidas de francés en castellano por don Juan Vitrián, con aforismos políticos, Amberes, año de 1643, en fol.» (Gutiérrez 1977: 222), o en casa del mismo Bartolomé Esteban Murillo, que antes de 1660 adquirió un ejemplar descrito como «Commines, con escolios de Vibrián (sic), un tomo» (Montoto 1946: 472)

Si atendemos al número de ejemplares de las obras del de Argentón, destaca la biblioteca del segundo duque de Pastrana, Rodrigo de Silva y Mendoza, que contaba con tres ejemplares distintos de las obras de Commynes: una edición italiana, otra francesa y un tercer ejemplar que desconocemos si se trataba de un manuscrito o un impreso:

- La historia famosa di monsignor di Argenton delle guerre e costumi di Ludouico undecimo re di Francia. Con la battaglia et morte del gran duca di Borgogna, tradotta a comune beneficio in lingua italiana. Opra degna

\footnotetext{
Para el estudio de la transmisión textual del texto de Vitrián y de la relación que mantiene con los Fracmentos de lugares concernientes a los Estados de Flandes (Zaragoza, 1636), ver Montes Pérez (2014).

8 A juzgar por el prólogo de Vitrián, ni él mismo conocía la traducción de Pedro de Aguilón, lo que demuestra el alcance limitado que tuvo la obra.

$9 \quad$ En el catálogo que se hizo de la biblioteca del Real Monasterio de San Martín de Madrid en 1788 también constaba la existencia de un volumen de las Memorias traducidas por Vitrián (IBSO: SM1-136r).
} 
da essere letta da ogni gran principe. In Venetia, Michel Tramezino, 1544 (Dadson 1998: 192).

- Les memoires de messire Philippe de Commines, cheualier, seigneur d'Argenton: sur les principaux faicts, \& gestes de Louis onzieme \& de Charles huictieme, son fils, roys de France, reueus \& corrigez par Denis Sauuage de Fontenailles en Brie... Paris, 1552. (Dadson 1988: 120).

- Otro libro a manera de oras yntitulado memorias de mesire felipe de comynes. (IBSO: RSM012; Dadson 1998: 340-341) ${ }^{10}$

También merece ser mencionada la biblioteca de Lorenzo Ramírez de Prado, mecenas, bibliófilo y literato que ocupó altos cargos en la administración durante el reinado de Felipe IV. Su librería contaba con cinco ejemplares de las obras del historiador francés: dos ediciones en italiano, una edición en latín publicada en Ámsterdam que incluía los textos de Commynes y de Frossard, la edición española de Juan de Vitrián y otra edición francesa publicada en París a finales de los años cuarenta.

- Commines, Memorias... en Italiano. Génova, 1594.

- Memorias de Comines, señor de Argenton, del Rey Luis XI y Carlos VIII en Italiano. Milán 1610 (IBSO: RP-II, 214).

- Frossoardus et Comines de rebus francorum. Amsterdam, 1640.

- Memorias... en Español, con Escolios por don Juan de Vitrián en un cuerpo. Ambers, 1643.

- Las Memorias... aumentadas en Francés. París, 1649 (Gutiérrez 1977: 196).

Si bien hemos podido comprobar que Commynes era uno de los autores casi indispensables en las librerías de muchos nobles y eruditos de principios de siglo, el interés que este escritor francés despertó en los monarcas de la casa de Austria se había iniciado algunos años antes, y por lo menos desde la época de Carlos V las Memorias eran una de las principales lecturas regias, consideradas, como ya había dicho Lipsio, una fuente de prudencia y de educación para el soberano ${ }^{11}$. Según el testimonio de Jehan Lhermite, humanista flamenco a quien

$\overline{10}$ Por la descripción, no queda muy claro a qué se refiere la expresión 'a manera de horas'. Quizá podría tener relación con el formato de los libros de horas o quizá podría hacer referencia a la encuadernación o al tamaño.

11 En el texto Campagne de Louis XIV se daba buena cuenta de ello: «Charles fit traduire 1'Histoire Philippes de Comines en toutes les langues qu'il sçavoit, afin d'imiter mieux le Duc de Bourgogne \& le Roy Louis XI parce qu'ils étoient souvent dispensez d'exécuter leurs promesses» (Pelisson 1730: 205). 
Felipe II le encomendó la instrucción del príncipe de Asturias, el futuro rey Felipe III, la formación del heredero pasaba por la lectura de Commynes:

Aquel invierno y los siguientes Su Alteza continuó ejercitándose mucho en la lectura, y leyó y releyó las mencionadas memorias del señor Philippe de Commines con grande atención, de tal modo que no se le escapaba una sola palabra de lo escrito por aquel autor, cuya lengua era no poco dificultosa y fuera de lo común, y copiaba de inmediato por escrito estas palabras en un librito de papel que le había hecho para esta sazón y que estaba dividido en diferentes partes por orden alfabético. Y aprendía él estas palabras todas las noches de memoria y de ellas sacó buen provecho y también con dichos vocablos mejoró la pronunciación, la cual supo imitar genuinamente. (Lhermite 2005: 267)

La lectura de obras historiográficas se había convertido en una pieza fundamental para la adquisición de conocimiento, pero pronto también la traducción de las mismas pasó a ser parte fundamental para la instrucción de príncipes (Montcher 2013: 47-53). Así lo afirmaba el mismo Felipe IV en su Autosemblanza, donde señalaba que había traducido al español la Historia de Guicchardini, y refería también la gran cantidad de libros de historia que había leído durante los dos primeros años de su reinado, es decir, entre 1621 y 1622:

Leí las historias de Castilla de los reyes D. Fernando el Santo, D. Alonso el Sabio, D. Sancho el Bravo, D. Fernando el cuarto (que llaman el Emplazado), la crónica de D. Alfonso el nono, las historias de D. Pedro el Justiciero o Cruel, D. Enrique el segundo y D. Juan el primero, la historia del Rey don Juan el segundo, con los Varones Ilustres de Fernán Pérez de Guzmán; las dos historias manuscritas del Rey D. Enrique el cuarto, las de los Reyes Católicos, la del Emperador Carlos V y mi bisabuelo, la Historia general de España, y los Varones Ilustres de Hernando del Pulgar; las de entrambas Indias, la historia y guerras de Flandes, la historia romana de los príncipes de ella, Salustio, Tito Livio, Cornelio Tácito y Lucano; la historia de Francia, la historia y guerras de Alemania, la campaña de Roma y la historia y cisma de Inglaterra. Fuera de esto, me pareció también leer diversos libros de todas lenguas, y traducciones de profesiones y artes, que despertasen y saboreasen el gusto de las buenas letras, y algunos ejemplos, aunque apócrifos, muy aventajados. (Seco Serrano 1958: 232-233)

Del catálogo de los libros que formaban parte de la biblioteca de Felipe IV, situada en la Torre Alta del Alcázar de Madrid, destaca la cantidad de volúmenes de historia que contenía, entre los cuales se encontraban tres ejemplares de las $\mathrm{Me}$ morias de Commynes (Bouza 2005: 283-285):

- Commynes, Philippe de. Cronique \& historie faicte et compose par feu messier Philippe de Commines... Paris, par Guillaume Thibout, 1549, $8^{\circ}$. 
- Commynes, Philippe de. Delle memorie di Filippo Comineo, cauagliero \& sig. d'Argentone, intorno alle principali attioni di Ludouico XI \& di Carlo VIII re di Francia lib. VIII. In Milano, apresso Gierolamo Bardoni, 1610, $8^{\circ}$.

- Commynes, Philippe de. Manuscrito. Historia de los Reyes de Francia Luys XI, Carlos VIII y su hijo, de Felipe de Comines.

Nos llama especialmente la atención la traducción manuscrita, que muy probablemente se enmarcase en el programa educativo que siguió Felipe IV para su propia formación en el gobierno de la monarquía; y aunque se ha especulado sobre la posible identificación de este códice, todo parece indicar que no se corresponde con ninguno de los ejemplares conservados hasta la fecha ${ }^{12}$. A principios de la década de los veinte, Manuel Filiberto de Saboya, virrey de Sicilia, tradujo las Mémoires de Commynes al castellano y le dedicó la obra al rey de España ${ }^{13}$. La fecha que consta en la dedicatoria cobra significado a la luz de las declaraciones regias anteriormente citadas. El virrey de Sicilia, y primo de Felipe IV, firmó la obra en enero de 1622, pocos meses después de la entronización del rey de España, y precisamente en el momento en el que este intensificó su formación en materias de estado a través de la lectura de obras historiográficas. En palabras del mismo Rey, estas obras eran «la verdadera escuela en que el Príncipe y el Rey hallarán ejemplares que seguir, casos que notar y medios por donde encaminar a buenos fines los negocios de la monarquía» (Seco Serrano 1958: 232).

Es muy probable que conociendo los intereses del nuevo Rey, Manuel Filiberto decidiera traducir la obra de Commynes al español y dedicársela a su primo para su mayor instrucción. Sin embargo, todo indica que el volumen no llegó a la corte española hasta después de la muerte de Manuel Filiberto, que tuvo lugar en 1624, ya que en su testamento legó el manuscrito al rey de España. Así se desprende de la inscripción del Ms. 17683 de la Biblioteca Nacional de España, donde aparece un prólogo firmado por don Antonio Hurtado de Mendoza en julio de 1627, en el que se afirma:

Este libro le tradujo de francés en castellano el señor príncipe Filiberto gobernando a Sicilia, y habiéndole dirigido al Rey Nuestro Señor, don Felipe Cuarto, se le dejó en su testamento y se le invió con un secretario suyo. Y habiéndole leído Su Majestad, como acostumbra leer todas las noches las historias de Castilla y extranjeras por habérselo suplicado ansí de los principios de su felicísimo reinado el Conde-Duque de Sanlúcar, me mandó a mí, don Antonio de Mendoza, su ayuda

12 Las hipótesis que se han barajado hasta el momento han relacionado este testimonio con el manuscrito custodiado en la Biblioteca del Escorial (ms. J.I.6.) y con el ms. 17638 de la Biblioteca Nacional de España. Ver García López (2013: 49) y Bouza (2005: 96).

13 Así se desprende de la dedicatoria de Manuel Filiberto a Felipe IV que aparece en los dos manuscritos reseñados en la nota anterior. 
de Cámara, que se llevase en su nombre para que Su Excelencia le pusiese en su librería ${ }^{14}$.

De estas afirmaciones se desprende que la traducción llegó a la corte después de la muerte de Manuel Filiberto de Saboya, que la leyó Felipe IV, y que en junio de 1627 se ordenó a Antonio de Mendoza que colocara un ejemplar, probablemente una copia del mismo, en la biblioteca del Conde-Duque, una librería que ya custodiaba algunas obras de Commynes. Gracias a las copias que se conservan del catálogo que el monje escurialense Lucas de Alaejos terminó en 1627, hemos podido documentar hasta cinco testimonios de las obras del señor de Argentón en la biblioteca del Conde-Duque ${ }^{15}$ :

- Commines. Chrónica... de las cosas de Luis 11 en Francia, Borgoña, Flandes, Artesia, Inglaterra y España. 8. París, 1539. Francés.

- Commines. Las memorias... en los tiempos del Rey Luis 11, hasta Carlos $8^{\circ}$. Fol. León. 1559. Francés.

- Commines. Historia del mismo Luis 11 y sus guerras. Y de Carlo Duque de Borgoña. Desde el año 1464. hasta 1559. $8^{\circ}$. Toscano.

- Commines. Historia de Carlos VIII y la Guerra de Nápoles. Traducida del latín por Joan Sleidano. 8. Argentorato. 1548.

- Mss. Commines. Chrónica del Rey Luis Onceno... traducida en castellano por un incierto. Tiene al cabo un tratadito del principio de la casa Real en Francia. En 4º (Gallardo 1968: IV, 1522; Gutiérrez 1977: 187).

Además de los impresos, el catálogo de Alaejos reseñaba una copia manuscrita en español de las Memorias de Commynes. Los datos expuestos hasta ahora nos inducen a pensar que este manuscrito podría ser el ejemplar ms. 17683 que se custodia en la Biblioteca Nacional de España y que contiene la anotación de Antonio Hurtado de Mendoza. Sin embargo, el estudio de la dispersión de la biblioteca del Conde-Duque que realizó Gregorio de Andrés en los años setenta identificó este manuscrito con el ms. J.I.6., que actualmente se conserva en la biblioteca del Escorial, ya que gran parte de los volúmenes de la librería de don Gaspar de Guzmán fueron a parar a los fondos escurialenses (Andrés 1973: 39 e IBSO: CDO0571) ${ }^{16}$. Si consideramos que efectivamente Antonio de Mendoza obedeció las órdenes reales e incorporó el otro manuscrito a la biblioteca del Conde-Duque, podríamos afirmar que la librería del valido contó con dos copias manuscritas de las

\footnotetext{
14 Se ha regularizado la ortografía y la puntuación del fragmento.

15 A pesar de que el catálogo manuscrito que realizó Alaejos se perdió, contamos con tres copias manuscritas del mismo. Ver Pereira Mira (2006: 275).

16 También Zarco Cuevas (1924: XVI) afirma que parte de los libros de la librería del Conde-Duque fueron a parar al Escorial.
} 
obras de Commynes, que además se corresponderían con los códices conservados en la actualidad ${ }^{17}$. Asimismo, el análisis ecdótico que se está llevando a cabo de estos manuscritos avalaría esta hipótesis, ya que revela que estos testimonios no son copia uno de otro (Sánchez Ruiz 2014: 241). Existe la posibilidad de que su antígrafo fuera el manuscrito original que tradujo Manuel Filiberto de Saboya y que habría llegado a la corte española después de la muerte del virrey ${ }^{18}$. En cualquier caso, todo este elenco de ejemplares reseñados daría cuenta de la fiebre por la lectura y la traducción de Commynes en los ambientes cortesanos españoles de la primera mitad del siglo XVII.

Para calibrar con más precisión la influencia de Philippe de Commynes en la literatura española conviene analizar también la presencia del historiador francés en los textos de la primera mitad del siglo XVII ${ }^{19}$. Una de las primeras citas del señor de Argentón la encontramos en las Rimas de Cristóbal de Mesa (Madrid, Alonso Martín), escritas entre 1605 y 1607 :

De alivio de solícitos cuidados nos sirven los toscanos estadistas, Argentón y el Paruta celebrados, que aunque no suelen ser evangelistas, vencen en el estilo y elegancia a muchos lisonjeros coronistas. El uno se dedica al rey de Francia y el otro a la Señoría de Venecia, y ambos tratan materias de importancia (vv. 61-69).

A lo largo de estos tercetos, donde Mesa enumeraba los libros de instrucción, se mencionaban Paolo Paruta y Philippe de Commynes entre los cronistas modernos, unos historiadores definidos como 'toscanos estadistas' que 'no suelen ser evangelistas'. Por una parte, se asoció al señor de Argentón con la zona de Italia, probablemente porque tuvo mucho contacto con el territorio y narró los sucesos de la Guerra de Italia; y por otra, y en el mismo sentido que recogía Vitrián en el prólogo de sus Memorias, Mesa destacó el hecho de que sus obras permitían lecturas que estaban al límite de la heterodoxia, pero sin caer en la herejía ni en el maquiavelismo (Ponce Cárdenas 2009: 105-106).

17 Es probable que Alaejos no incorporara el segundo manuscrito en el catálogo si a primeros de julio de 1627 ya tenía terminado su inventario.

18 Este manuscrito podría haberse custodiado en la biblioteca de la Torre Alta, correspondiéndose así con el manuscrito descrito por Bouza (2005: 285).

19 A finales del siglo XVI encontramos algunas de las primeras menciones al historiador francés. El padre Ribadeneyra apreció la simplicidad de Commynes en el Tratado de la religión y virtudes (1595), y el padre Mariana también lo citó en la Historia General de España.

Edad de Oro, XXXIV (2015), pp. 101-114, ISSN: 0212-0429 
Sin abandonar estos ambientes italianos, encontraremos una nueva referencia a Commynes en la primera redacción de República Literaria, una obra que ofrece una revisión crítica del ideal cultural europeo escrita muy probablemente en Italia hacia 1615-1620, donde el señor de Argentón aparece como uno de los pocos historiadores en romance que merecían ocupar un lugar en el templo de los elegidos. En 1616, Alvia de Castro citó al historiador francés en su Verdadera razón de Estado, una obra de claro cuño político, donde destacaba la prudencia del francés. En 1620, también lo hizo Antonio de Vera y Figueroa, conde de la Roca, cuando citó repetidas veces a Commynes en El Embajador (Sevilla, Francisco de Lyra), una obra que presentaba un modelo de gobernante basado en Baltasar de Zúñiga. Además, las páginas preliminares de la obra estaban decoradas por un grabado de Felipe III donde aparecía sosteniendo un yelmo encima de un ejemplar de Las Memorias de Commynes (Montcher 2013: 47).

En la década de los cuarenta cabe destacar la aparición del historiador francés en El político, donde Baltasar Gracián lo comparó con Tácito: «Quedo invidiando a Tácito y a Commynes las plumas, mas no el centro; el espíritu, mas no el objeto ${ }^{20}$. El de Argentón también estuvo presente en la segunda redacción de República Literaria que firmó Diego de Saavedra y en la Cataluña desengaña$d a$ de Alejandro de Ros, una obra de propaganda política a favor de Felipe IV en plena Guerra dels Segadors. A principios de los años cincuenta vuelve a figurar en El Criticón, citado como uno de los grandes historiadores al lado de Homero, Virgilio, Plinio y Tácito («la [pluma] más plausible de todas» entre los modernos autores de Historia), y también es mencionado por Francisco Manuel de Melo en su Hospital das letras, una obra de crítica literaria que se inscribe en la línea de los Ragguagli di Parnaso di Traiano Boccalini y de la República literaria, y en la cual se elogiaban los comentarios políticos de Vitrián a la obra de Commynes.

De este elenco de obras se desprende que los escritores españoles conocieron las obras de Commynes mucho antes de la traducción española hecha por Juan de Vitrián en 1643. Como demuestran los catálogos de las bibliotecas que hemos analizado, las obras del historiador se difundieron y se leyeron en francés, italiano y latín. Sin embargo, lo que llama la atención es esta presencia notable de citas de Commynes en textos de cuño político durante la primera mitad del siglo XVII. No hay duda de que en comparación con otros países, el interés de los autores españoles por el historiador francés es tardío y que la primera traducción impresa en español, la que publicó Pedro de Aguilón en 1586, pasó prácticamente desapercibida y tuvo una escasísima repercusión, como demuestra, por ejemplo, que no la hayamos encontrado consignada en ninguno de los catálogos analizados.

20 Blanco (2014: 16) apunta al posible encuentro entre Gracián y Juan de Vitrián durante la estancia de este último en la corte alrededor de los años 1641-1642, o bien cuando el último fue prior y provisor de Calatayud. 
Todo parece indicar que en los ambientes cortesanos españoles, el interés por la figura de Felipe de Commynes no surgió hasta entrado el siglo XVII y muy probablemente vinculado a la cuestión de la ética y la moralidad en la ciencia política, como alternativa a las doctrinas del secretario florentino y con la voluntad de situar las ideas de la Razón de Estado dentro de la ortodoxia cristiana (García López 2013: 63). Asimismo, parece que uno de los principales eruditos europeos de finales del XVI, Justo Lipsio, también tuvo un papel destacado en la revitalización de Commynes.

No hay duda de que Justo Lipsio abanderó las corrientes intelectuales de vanguardia en la Europa del siglo XVI y XVII. Sus ideas neoestoicas calaron hondo en gran parte de los escritores españoles del momento. A nivel estético, reivindicó un nuevo estilo literario cuyas máximas eran la brevedad y la agudeza, basado en Tácito, Séneca y Plinio el Joven, que rompiera con los preceptos del humanismo quinientista de raíz ciceroniana; un estilo que sin duda marcó a los grandes prosistas políticos del momento, desde Virgilio Malvezzi hasta Francisco de Quevedo, Diego de Saavedra Fajardo o Baltasar Gracián. Por otra parte, su obra Satyra Menippaea. Somnium, publicada en Amberes el 1581, sin duda revalorizó el género grecolatino de la sátira menipea, que cultivaron autores como Traiano Boccalini o los ya mencionados Quevedo y Saavedra Fajardo.

No parece ser casual, pues, que Lipsio mencionara a Philippe de Commynes en los comentarios a los seis libros de la Política publicados en 1598, donde destacaba que a pesar de no ser un hombre de letras, Commynes poseía una prudente experiencia, iluminada de un buen juicio natural, con la que había hecho mucho más que algunos clásicos ${ }^{21}$. Para Lipsio, los textos de Commynes debían ser una lectura obligada para los príncipes porque de ellos extraerían buenas lecciones y enseñanzas: «At Princeps noster hung legito, et Enchiridium Cominaeus illi esto» (Lipsius 1604: 18-19). De la mano del mismo Lipsio, que había recomendado la historia como fuente de prudencia y erudición para monarcas, ahora se ensalzaba a Commynes como breviario político para los reyes y como consejero prudente en materias de estado. Se convirtió en una alternativa a los clásicos y en un antídoto contra el innombrable secretario florentino. Las obras de Commynes podían

21 Ver Lipsius (1604: 18-19). Transcribo la traducción al francés del fragmento latino: «Philippe de Comines mit la main à la plume, avec tant de réputation, que je ne crains point de l'assortir avec quiconque l'on voudra des anciens. L'on ne sçauroit croire combien ce personnage est adroit à se porter par tout, pour ne rien laisser qu'il ne sonde jusques au fond, tirant le plus clair des conseils d'Estat, nous enrichissant d'enseignements d'estile et de très grand usage, voire au long a l'imitation de Polybe, lequel il n'avoit leu, ni autre historien de telle estoffe. Ce qui le recommande encore d'avantage, veu que n'estant homme de lettres, ains seulement douté de prudente expérience, esclairée d'un bon jugement naturel, il a fait plus que beaucoup de sçavans. Que notre Prince le lise; que Commines soit son bréviaire. Ce Philippe est digne de tous les Alexandres du monde» (Lipsius 1613: 54). 
ser leídas como textos tacitistas, y el de Argentón se había convertido en el nuevo Tácito, con el que era sistemáticamente comparado, y su utilización pasó a ser frecuente por parte de los escritores que se inscribieron en esta corriente de pensamiento político-filosófico, como ocurrió con Boccalini o Ammirato.

El elogio de Lipsio a la figura de Commynes no pasó desapercibido por sus contemporáneos, tal y como demuestra la afirmación de Lorenzo Conti, uno de los traductores al italiano de las obras de Commynes: «Si cet historien était vivant, il serait loué pour [...] avoir été jugé digne et singulier par Juste Lipse pour la lecture des Princes» (Gorris 2005: 132). Por su parte, los escritores españoles tampoco tardaron en acoger la doctrina de Lipsio, tal y como demuestra la mención del señor de Argentón que aparece en la primera redacción de República Literaria: «Después de la declinación del imperio, apenas hay quien merezca nombre de historiador si no es Felipe Comines, que aunque desnudo de ciencias, con su buen natural juicio se igualó a los antiguos; es maravilloso en penetrar las causas de los sucesos y en dar consejos" (Saavedra Fajardo 2006: 132) 22. En este caso, parece evidente que los sintagmas 'desnudo de ciencias', 'natural juicio' e 'igualó a los antiguos' se deben a la atenta lectura de los elogios que le dedicó Lipsio. Y precisamente como alternativa a los clásicos y en la línea de conjugar la Razón de Estado con la ética cristiana, se pronunció el deán de Sigüenza en la licencia de impresión que precede la traducción de Vitrián, donde afirmaba de Commynes: «Autor político, igualmente católico, y en su comentador erudito, sin que los príncipes y sus consejeros tengan que andarlo buscando en infinitos otros antiguos y modernos». Para los escritores políticos de principios del XVII, Commynes se postulaba como el nuevo Tácito.

A la luz de lo señalado, la relevancia de Commynes en la España de principios del siglo XVII se debería principalmente a la confluencia de dos circunstancias: la discusión sobre la Razón de Estado y la necesidad de encauzar las doctrinas maquiavélicas hacia la ortodoxia católica, y la alabanza de Lipsio, que autorizó a Commynes como un escritor digno de pertenecer a la esfera del tacitismo político. Estas ideas calaron hondo en un momento de debate profundo entre moral y política, que convirtió al señor de Argentón en símbolo de la prudencia política; tal y como lo definió Charles Augustin Sainte-Beuve, en 'Machiavel en douceur'.

\footnotetext{
22 Fueron varios los escritores que destacaron la falta de estudios del señor de Argentón, como lo advirtió también Vitrián en los preliminares a su traducción: «Lamentose toda su vida de que le criaren sin letras».
} 


\section{OBRAS CITADAS}

ANDRÉs, Gregorio de (1973). «Historia de la biblioteca del Conde-Duque de Olivares y descripción de sus códices». Cuadernos Bibliográficos, 30, pp. 5-73.

Blanco, Emilio (2014). «Guzmán de Alfarache, el canon teórico del siglo XVII y un modelo de Agudeza». Komparatistik online, 1, pp. 3-25.

Bouza, Fernando Jesús (2005). El libro y el cetro. La biblioteca de Felipe IV en la Torre Alta del Alcázar de Madrid. Salamanca: Instituto del Libro y la Lectura.

DADSON, Trevor J. (1987). «Inventario de los cuadros y libros de Ruy Gómez de Silva, III Duque de Pastrana (1626)». Revista de Filología Española, 62.3-4, pp. 245-268. (1998). Libros, lectores y lecturas: estudios sobre bibliotecas particulares españolas del Siglo de Oro. Madrid: Arco Libros.

(2008). «Las bibliotecas de la nobleza: dos inventarios y un librero, año de 1625». En Aurora Egido y José Enrique Lapana (eds.), Mecenazgo y Humanidades en tiempos de Lastanosa. Homenaje a Domingo Ynduráin. Zaragoza: Institución Fernando el Católico, pp. 253-302.

Domingo Malvedí, Arantxa (2010). Disponiendo anaqueles para libros. Nuevos datos sobre la biblioteca de Jerónimo Zurita. Zaragoza: Institución Fernando el Católico.

EsPINo LóPEZ, Antonio (2001). «La biblioteca de don Joaquin Setantí. Las lecturas de un tacitista catalán». Bulletin Hispanique, 103, pp. 43-73.

Gallardo, Bartolomé José (1968). Ensayo de una biblioteca española de libros raros y curiosos. Madrid: Gredos.

GARCía LóPeZ, Jorge (2013). «Philippe de Commynes en España: materiales para un estudio». Boletín de la Real Academia Española, 93, 307, pp. 45-67.

GorRIS, Rosanna (2005). «La France estoit affamée de la lecture d'un tel historien: lectures de Tacite entre France et Italie». Écritures de l'Histoire (XIV - XVI siècle). Genève: Droz, pp. 113-142.

GutiérReZ, Asensio (1977). La France et les français dans la littérature espagnole. SaintÉtienne: Publications de l'Université de Saint-Étienne.

LHERMITE, Jeham (2005). El Pasatiempos de Jeham Lhermite: memorias de un gentilhombre flamenco en la corte de Felipe II y Felipe III. Jesús Sáenz de Miera \& José Luis Checa Cremades (eds). Aranjuez: Doce Calles.

LiPsius, Justus (1604). Ad libros politicorum notae. Antverpiae: Ioannem Moretum. - (1613). Les politiques de Juste Lipsius. Genève: Pierre \& Jaques Chovet.

MonTCHER, Fabián (2013). Historiografia real en el contexto de la interacción hispano-francesa (1598-1635). [Tesis doctoral]. Madrid: Universidad Complutense de Madrid.

Montes PÉREZ, Dámaris (2014). La transmisión textual de las Mémories de Philippe de Commynes en las traducciones de Felipe (1636) y Juan de Vitirán (1643). [Trabajo de Final de Máster]. Girona: Universitat de Girona.

Montoto, Santiago (1946). «La biblioteca de Murillo». Bibliografia Hispánica, 7, pp. 467-479.

Pellisson-Fontanier, Paul (1730). Campagne de Louis XIV, avec la comparaison de François I avec Charles-Quint. Paris: Mesnier.

Pereira Mira, Carlos Benjamín (2006). «Éxodo librario en la biblioteca capitular de Oviedo: el Codex miscellaneous ovetensis». Territorio, Sociedad y Poder, 1, pp. 263-278. 
Ponce CÁrdenas, Jesús (2009). «Góngora y el conde de Niebla. Las sutiles gestiones del mecenazgo». Criticón, 106, pp. 99-146.

SaAVEdRa FajARdo, Diego de (2006). República literaria. Jorge García López (ed.). Barcelona: Crítica.

SÁNCHEZ RuIZ, Mariona (2014). «Arquetipos del poder político: lecturas de Philippe de Commynes en la corte de Felipe IV». Cahiers de Recherches Interdisciplinaires et Transculturelles, 6, pp. 239-250.

Seco Serrano, Carlos (ed.) (1958). Autosemblanza de Felipe IV. Biblioteca de Autores Españoles. Madrid: Atlas, t. 109, pp. 231-236.

Zarco Cuevas, Julián (1924). Catálogo de los manuscritos castellanos de la Real Biblioteca de El Escorial. Madrid: Real Biblioteca de El Escorial, vol. 1.

Libros y librerías: la recepción de Commynes en españa

Resumen: Este artículo pretende arrojar nueva luz sobre la influencia que tuvieron las obras del historiador francés Philippe de Commynes en la literatura española de principios del siglo xvii. Para ello se van a rastrear los catálogos de las principales librerías españolas del Siglo de Oro y se va a analizar la utilización del historiador por parte de los escritores políticos de la primera mitad de siglo. En un contexto en el que se intensificó el debate sobre la Razón de Estado, la influencia de Justo Lipsio fue decisiva para revitalizar la figura de Commynes en España, encumbrándolo como escritor prudente, político y ortodoxo.

Palabras clave: Philippe de Commynes, España, bibliotecas, educación de príncipes, Lipsio.

\section{Books and libraries: the reception of Commynes in Spain}

ABSTRACT: This article aims to analyse the influence of the works of the French historian Philippe de Commynes in Spanish literature of the early seventeenth century. For this purpose, we will locate his works in the catalogues of the main libraries of Spanish Golden Age and we will analyse the using of the historian by the political writers of the first half of the century. In a context where the discussion on the Reason of State was intensified, the influence of Justus Lipsius was crucial to revitalize the figure of Commynes in Spain, exalting him as a prudent, political and orthodox writer.

Keywords: Philippe de Commynes, Spain, libraries, education of princes, Lipsius. 
TERESA DE JESÚS (1515-1582)

Guillermo Serés (Universidad Autónoma de Barcelona)

La imaginación de Santa Teresa: virtudes y desatinos de «la loca de la casa»....... 11

Ana Garriga EsPino (Universidad Autónoma de Madrid)

El desafío editorial de las cartas de Teresa de Jesús.

LeCTURAS REPUBLICANAS DEL QUIJOTE

RAQUEL ArIas (Universidad Autónoma de Madrid)

León Felipe alista a don Quijote en el bando republicano. 57

MANUEl LóPez ForJas (Universidad Autónoma de Madrid)

El Quijote y la realidad viva de las Españas: la visión histórica

de Pedro Bosch-Gimpera.

CArmen Madorrán Ayerra (Universidad Autónoma de Madrid)

El Quijote como utopía necesaria: la mirada de Adolfo Sánchez Vázquez 85

\section{OTROS TEMAS}

SònIA BoADAS (Universitat Autònoma de Barcelona)

Libros y librerías: la recepción de Commynes en España 101

Lucila Lobato Osorio (Universidad Nacional Autónoma de México)

La noticia de la muerte de Policisne de Boecia: expresiones de dolor en un libro inconcluso.

María Gutiérrez Padilla (Universidad Nacional Autónoma de México)

La escenografía en el teatro caballeresco 131

ADRIÁn FERnÁNDEZ (Université de Fribourg)

Dos entremeses «auditivos» y sus niveles: hacia un metateatro visual. 145

David González de la Higuera Garrido (Universidad Complutense de Madrid) La visión premonitoria de Alonso en El caballero de Olmedo:

otra recuperación de lo popular

Esther Fernández LóPEz (UNED)

Perseo en la comedia tardobarroca: Ignacio Ferrera y Pasqual 169

Manuel Piqueras Flores (Universidad Autónoma de Madrid)

De La hija de Celestina $a$ La ingeniosa Elena: estructura narrativa, género literario e interpolación 
Dagoberto CÁceres Agullar (Western University Canada)

Realismo incesante: desde Celestina hacia su recepción 201

TeXTOS INÉDITOS

Davinia Rodríguez Ortega (Universidad Pública de Navarra)

Auto sacramental del Juego del Hombre, de Luis Mejía de la Cerda:

edición crítica 


\section{EDAD DE ORO}

Revista de Filología Hispánica XXXIV

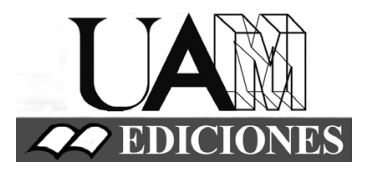




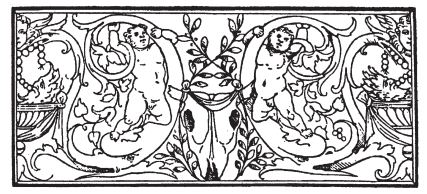

\section{Edad de Oro. Revista de Filología Hispánica}

ISSN: 0212-0429

Dirección:

Teodosio Fernández

Secretaría y edición:

José Ramón Trujillo

Comité científico internacional:

Carlos Alvar (Univ. de Ginebra)

Ignacio Arellano (Univ. de Navarra)

Javier Blasco (Univ. de Valladolid)

Alberto Blecua (UAB)

Jean Canavaggio (Univ. de París X)

Laura Dolfi (Univ. de Turín)

Aurora Egido (Univ. de Zaragoza)

Víctor García de la Concha (RAE)

Luciano García Lorenzo (CSIC)

Joaquín González Cuenca (Univ. de Castilla-

La Mancha)

Agustín de La Granja (Univ. de Granada)

Begoña López Bueno (Univ. de Sevilla)

Michel Moner (Univ. de Toulouse III)

Joan Oleza (Univ. de Valencia)

Alfonso Rey (Univ. de Santiago)

Lina Rodríguez Cacho (Univ. de Salamanca)

Leonardo Romero Tobar (Univ. de Zaragoza)

Aldo Ruffinatto (Univ. de Turín)

Lía Schwartz (City University of New York)
Redacción y admisión de originales:

Teodosio Fernández

Edad de Oro

Departamento de Filología Española

Universidad Autónoma de Madrid

28049 Madrid (España)

Tfno.: +0034914974090

correo: teodosio.fernandez@uam.es

Distribución, suscripción y venta:

Servicio de Publicaciones de la UAM

Universidad Autónoma de Madrid

28049 Madrid (España)

Intercambio de publicaciones:

Biblioteca de la Facultad de Filosofía y

Letras (UAM)

Universidad Autónoma de Madrid

28049 Madrid (España)

Han colaborado en este volumen:

Departamento de Filología Española (UAM)

Facultad de Filosofia y Letras (UAM)

Edad de Oro se recoge, entre otras, en las siguientes bases de datos: SCOPUS, MLA Database, HLAS, Latindex, PIO-Periodical Content Index, ISOC, Dialnet, MIAR, ERIH, DICE, Sumaris CBUC, Ulrich's. Se encuentra evaluada en CIRC: A; INRECH; MIAR difusión ICDS live: 9.977; SCImago Journal \& Country Rank: H Index 2, SJR 0,101, Q4; RESH índice de impacto: 0.041; ERIH: A INT1; Carhus Plus+ 2014: C. 